\title{
Searching for the Lost Road of the Non-Invasive Positive Pressure Ventilation in the Acute Respiratory Distress Syndrome
}

\author{
Óscar Peñuelas, Fernando Frutos-Vivar, Andrés Esteban \\ Hospital Universitario de Getafe, Spain. CIBER de Enfermedades Respiratorias, Spain
}

Cite this article as: Peñuelas Ó, Frutos-Vivar F, Esteban A. Searching for the Lost Road of the Non-Invasive Positive Pressure Ventilation in the Acute Respiratory Distress Syndrome. Eurasian J Emerg Med 2017; 16: 90-1

The role of non-invasive positive pressure ventilation (NPPV) in the management of the acute respiratory distress syndrome (ARDS) is controversial. Despite several studies have confirmed that although NPPV may avoid the need for invasive mechanical ventilation in ARDS patients, there is a concern regarding the clinical outcomes of critically ill patients who fail a trial of NPPV, and need invasive mechanical ventilation. This effect may be explained because of the generally high likelihood of failure and the risks associated with a delay in starting invasive mechanical ventilation.

It is clear the growing interest of the application of NPPV in ARDS. In fact, the rate of ARDS patients ventilated with NPPV as first ventilatory attempt has increased over time, ranging from $6 \%$ in $1998,12 \%$ in 2004, and reached up to $24.5 \%$ in 2010 (1-3). The failure of NPPV in these observational studies, was $61 \%$ (1-3).

Based on an analysis of 13 studies involving 540 patients, Agarwal et al. (4) found that, in ARDS patients treated with NPPV, the intubation rate ranged from $30 \%$ to $86 \%$, with a pooled intubation rate of $48 \%(95 \% \mathrm{Cl}, 39 \%$ to $58 \%$ ), and the mortality rate ranged from $15 \%$ to $71 \%$, with a pooled mortality rate of $35 \%$ ( $95 \% \mathrm{Cl}, 26 \%$ to $45 \%)$. In the third international study of mechanical ventilation carried out in 2010, our group found that ICU and hospital mortality were higher in ARDS patients who failed an attempt of NPPV, compared with those that underwent invasive mechanical ventilation as first ventilatory support (60\% vs. $47 \%$ for ICU mortality, and $70 \%$ vs. $53.5 \%$ for hospital mortality, respectively, unpublished data).

Importantly in this sense, Bellani et al. (5) has highlighted the use of NPPV in the largest cohort of patients with ARDS. One of the main finding of the study was that NPPV failure occurred in $37.5 \%$ of patients with ARDS, showing a trend of greater risk of failure depending on the severity of ARDS. Secondly, NIV failure was associated with a striking increase in the risk of death, with mortality higher than for severe ARDS underwent invasive mechanical ventilation as first line (hazard ratio, 1.446 [95\% confidence interval, 1.159-1.805]). After adjusting for potential confounders, a patient treated with NPPV at ARDS onset seemed to have a $30 \%$ increased risk of dying in ICU compared with a similar patient treated with invasive mechanical ventilation. Furthermore, in the propensity-matched cohort, the ICU mortality was significantly higher for NPPV than for invasive-mechanical ventilation in the cohort of patients with $\mathrm{PaO}_{2} / \mathrm{FiO}_{2}$ ratio lower than 150 (36.2\% with NIV compared with $24.7 \%$ with invasive-mechanical ventilation $(p=0.033)$.

Thus, this parameter could be used at bedside to stratify patients when deciding to treat patients with NPPV or in deciding to terminate NPPV and proceed to invasive mechanical ventilation.

These findings raise further concerns regarding NPPV use in patients with ARDS. Given the higher than expected mortality in patients who failed a trial of NPPV, it should be instituted with extreme caution in ARDS patients, and preferably selecting other therapeutic approaches. Frat et al. (6) found that conditioned nasal cannula highflow oxygen therapy, as compared with standard oxygen therapy or noninvasive ventilation, resulted in reduced mortality in the ICU and at 90 days among patients with acute hypoxemic respiratory failure (hazard ratio for death at 90 days after randomization was 2.01 in the standard oxygen group versus the high flow oxygen group $(p=0.046)$, and 2.5 in the NPPV group versus the high flow oxygen group ( $p=0.006)$.

Thus, based on the previous available data, NPPV cannot be recommended as a routine ventilatory strategy for ARDS, and it supports a cautious trial in highly selected patients with a $\mathrm{PaO}_{2} / \mathrm{FiO}_{2}$ ratio $>150$ readiness to promptly intubate if oxygenation fails to improve sufficient- 
ly. The application of this ventilatory strategy is pending of the confirmation of the results for the implementation of the conditioned nasal cannula high flow oxygen in this group of patients with further studies.

In conclusion, only a minority of very well selected ARDS patients are candidate to use NPPV as ventilatory strategy and in case of choosing it, carefulness is advised to recognize the failure of NPPV early, with promptly making the decision of invasive mechanical ventilation. It is essential in this type of patients to have a chair at bedside, as a clinical tool to apply adequate mechanical ventilation.

\section{References}

1. Esteban A, Frutos-Vivar F, Muriel A, Ferguson ND, Peñuelas O, Abraira V, et al. Evolution of mortality over time in patients receiving mechanical ventilation. Am J Respir Crit Care Med 2013; 188: 220-30. [CrossRef]
2. Esteban A, Ferguson ND, Meade MO, Frutos-Vivar F, Apezteguia C, Brochard $\mathrm{L}$, et al. Evolution of mechanical ventilation in response to clinical research. Am J Respir Crit Care Med 2008; 177: 170-7. [CrossRef]

3. Esteban A, Anzueto A, Frutos F, Alía I, Brochard L, Stewart TE, et al. Characteristics and outcomes in adult patients receiving mechanical ventilation: a 28-day international study. JAMA 2002; 287: 345-55. [CrossRef]

4. Agarwal R, Aggarwal AN, Gupta D. Role of noninvasive ventilation in acute lung injury/acute respiratory distress syndrome: a proportion meta-analysis. Respir Care 2010; 55: 1653-60.

5. Bellani G, Laffey JG, Pham T, Madotto, Fan E, Brochard L, et al. Noninvasive Ventilation of Patients with Acute Respiratory Distress Syndrome. Insights from the LUNG SAFE Study. Am J Respir Crit Care Med 2017; 195: 67-77. [CrossRef]

6. Frat JP, Thille AW, Mercat A, Girault C, Ragot S, Perbet $S$, et al. REVA Network: High flow oxygen through nasal cannula in acute hypoxemic respiratory failure. N Engl J Med 2015; 372: 2185-96. [CrossRef] 